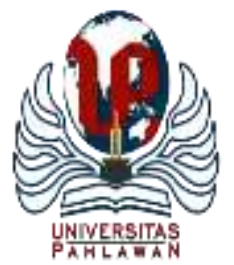

Edukatif : Jurnal Ilmu Pendidikan Volume 3 Nomor 6 Tahun 2021 Halm 3779 - 3785

EDUKATIF: JURNAL ILMU PENDIDIKAN

Research \& Learning in Education

https://edukatif.org/index.php/edukatif/index

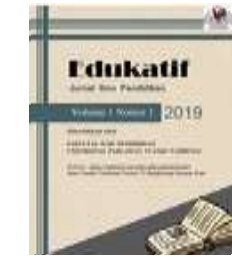

\title{
Pengaruh Media Pembelajaran Berbasis Youtube terhadap Hasil Belajar IPA Siswa di Sekolah Dasar
}

\author{
Amalia Rizki Wulandari ${ }^{1 凶}$, Masturi $^{2}$, Fina Fakhriyah ${ }^{3}$ \\ Pendidikan Guru Sekolah Dasar, FKIP UniveristasMuria Kudus ${ }^{1,2,3}$ \\ E-mail : amaliarizki026@gmail.com ${ }^{1}$
}

\begin{abstract}
Abstrak
Penelitian ini dilatarbelakangi karena menurunnya hasil belajar siswa saat proses pembelajaran daring selama masa pandemi. Penelitian bertujuan untuk mengetahui ada atau tidaknya pengaruh media pembelajaran berbasis youtube terhadap hasil belajar ipa siswa sekolah dasar. Dalam penelitian ini menggunakan metode Quasi Eksperimental Design dengan desain penelitian The Nonequivalent pretest-posttest control-group. Pengumpulan data dalam penelitian ini menggunakan instrumen tes, dengan populasi berjumlah 26 siswa. Analisis data menggunakan uji-t dua sampel independent pada taraf signifikansi 5\%. Penggunaan media pembelajaran berbasis youtube dapat memberikan pengaruh baik terhadap hasil belajar siswa, sebagaimana hasil penelitian didapatkan hasil, belajar IPA kelas eksperimen sebesar 84,23 dan nilai rata-rata post-test kelas kontrol sebesar 79,92. Maka berdasarkan data tersebut kelas eksperimen memiliki rata-rata hasil belajar IPA lebih tinggi dibandingkan kelas kontrol. Analisis data hasil belajar menunjukkan bahwa nilai sig. (2-tailed) 0,001 < 0,05. Maka dapat disimpulkan bahwa Ho ditolak dan Ha diterima yang artinya terdapat perbedaan yang signifikan antara hasil belajar IPA kelas eksperimen dan kelas kontrol. Hal ini menunjukkan bahwa terdapat pengaruh media pembelajaran berbasis youtube terhadap hasil belajar ipa siswa kelas $\mathrm{v}$ sekolah dasar tema 7 materi kalor.
\end{abstract}

Kata Kunci: Media Pembelajaran, Youtube, Hasil Belajar IPA.

\begin{abstract}
This research is motivated by the decline in student learning outcomes during the online learning process during the pandemic. This study aims to determine whether or not there is an influence of YouTube-based learning media on elementary school students' science learning outcomes. In this study using the Quasi Experimental Design method with the research design The Noneequivalent pretest-posttest control-group. Collecting data in this study using a test instrument, with a population of 26 students. Data analysis used two independent sample t-test at a significance level of $5 \%$. The use of youtube-based learning media can have a good influence on student learning outcomes, as the results of the study obtained, learning science in the experimental class was 84.23 and the average post-test score for the control class was 79.92. So based on these data the experimental class has a higher average science learning outcome than the control class. Analysis of learning outcomes data shows that the value of sig. (2-tailed) $0.001<0.05$. So it can be concluded that Ho is rejected and Ha is accepted, which means that there is a significant difference between the learning outcomes of the experimental class and the control class. This shows that there is an influence of YouTube-based learning media on the science learning outcomes of fifth grade elementary school students with the theme 7 heat material.
\end{abstract}

Keywords: Learning Media,Youtube,Science Learning Outcomes.

Copyright (c) 2021 Amalia Rizki Wulandari, Masturi, Fina Fakhriyah

$\triangle$ Corresponding author

Email : amaliarizki026@gmail.com

DOI $\quad$ : https://doi.org/10.31004/edukatif.v3i6.1251

ISSN 2656-8063 (Media Cetak)

ISSN 2656-8071 (Media Online)

Edukatif : Jurnal Ilmu Pendidikan Vol 3 No 6 Tahun 2021 p-ISSN 2656-8063 e-ISSN 2656-8071 
3780 Pengaruh Media Pembelajaran Berbasis Youtube terhadap Hasil Belajar IPA Siswa di Sekolah DasarAmalia Rizki Wulandari, Masturi , Fina Fakhriyah

DOI: https://doi.org/10.31004/edukatif.v3i6.1251

\section{PENDAHULUAN}

Pembelajaran merupakan suatu proses interaksi antara siswa dengan guru yang saling mempengaruhi untuk mencapai sebuah tujuan pembelajaran. Belajar merupakan suatu kegiatan untuk meningkatkan kecerdasan, ilmu, perubahan perilaku (Arfani, 2018). Guru sebagai pendidik dalam proses pembelajaran berperan sebagai unsure pemberi, penyalur, dan penyampai ilmu, sehingga dalam meningkatkan kualitas pembelajaran yang lebih baik maka diperlukan adanya perbaikan dalam proses pembelajaran salah satunya dengan media pembelajaran. Tujuan belajar yaitu menciptakan pengalaman yang akan menjadi landasan kehidupan bagi siswa (Salam, 2017). Dalam proses pembelajaran perlu adanya media pembelajaran yang dapat membantu menunjang dalam menyampaikan sebuah materi. Media pembelajaran adalah sesuatu yang terdiri dari bahan, alat atau teknik yang digunakan dalam kegiatan belajar mengajar dan membantu siswa memahami masalah yang abstrak (Zayyadi et al., 2017).

IPA meruapakan salah satu mata pelajaran yang utama di sekolah dasar. Ilmu Pengetahuan Alam merupakan suatu pembelajaran yang membahas tentang keadaan alam semesta dan proses ilmiah sehingga siswa dapat melakukan pembelajaran sesuai dengan proses ilmiah seperti, mengamati, mengklasifikasi, memprediksi, merancang dan melaksanakan eksperimen. Pengetahuan pelajaran IPA dapat diperoleh dengan kegiatan berupa fakta, konsep dan teori. Untuk itu diperlukan cara dan media yang tepat dalam proses pembelajaran agar mempermudah siswa untuk memahami materi.

Hasil belajar adalah kemampuan-kemampuan yang dimiliki siswa setelah ia menerima pengalaman belajar (Sudjana, 2011). Untuk mengetahui keberhasilan siswa dalam belajar maka digunakan evaluasi atau penilaian. Berdasarkan observasi peneliti menemukan rendahnya hasil belajar siswa dikarenakan dampak pembelajaran daring pada saat pandemi. Hal ini karena siswa kesulitan memahami materi pembelajaran. Proses pembelajaran jarak jauh ini menyebabkan minat dan focus siswa menjadi menurun siswa menjadi pasif dalam pembelajaran sehingga mempengaruhi nilai siswa (Cahyani et al., 2020). Tantangan dalam proses pembelajaran IPA yang dihadapi guru salah satunya yaitu dalam menyampaikan materi karena proses pembelajaran dilakukan secara daring. Hal ini dapat menyebabkan pemahaman siswa terhadap materi pembelajaran yang disampaikan kurang maksimal. Selain itu, dalam proses pembelajaran secara daring guru dituntut untuk mahir dalam mengoperasikan teknologi. Yang digunakan untuk membantu peralihan pembelajaran dari proses pembelajaran tatap muka ke pembelajaran virtual. Pembelajaran daring yang dilakukan secara online merupakan salah satu solusi dari berbagai masalah yang terkait dengan hasil belajar kognitif siswa (Jannah \& Nurdiyanti, 2021).

Untuk menghadapi masalah tersebut, guru harus memberikan proses pembelajaran yang tepat dengan menggunakan media pembelajaran IPA yang menarik, edukatif dan menyenangkan. IPA merupakan suatu konsep pembelajaran alam dan mempunyai hubungan yang sangat luas terkait dengan kehidupan manusia. Selama ini proses pembelajaran IPA di SD Karangsari 01 dengan metode ceramah dengan mengirim rekaman suara guru melalui group di android dan tugas mandiri yang dikerjakan dirumah masing-masing siswa. Maka dari itu dibutuhkan media pembelajaran yang sesuai untuk menunjang proses pembelajaran IPA. Pemilihan media pembelajaran yang tepat akan menarik minat siswa untuk melaksanakan pembelajaran dengan menyenangkan, sehingga tujuan pembelajaran dapat tercapai dengan optimal. Media merupakan alat bantu yang dapat memudahkan pekerjaan. Media merupakan wahana penyalur informasi belajar atau penyalur pesan (Rusman, 2013). Ada berbagai media pembelajaran berbasis teknologi yang dapat digunakan dalam proses pembelajaran daring. Ada Whatsapp, Google Classroom, Zoom Meeting, Youtube dan masih banyak lainnya. Youtube adalah video online dan yang utama dari kegunaan situs ini adalah sebagai media untuk mencari, melihat dan berbagi video yang asli ke dan dari segala penjuru dunia melalui suatu web (Bugiardo, 2015). Dari beberapa media pembelajaran daring tersebut, media pembelajaran youtube merupakan salah satu media yang menarik untuk dijadikan pilihan media saat pembelajaran daring. Didalam media youtube guru dapat 
3781 Pengaruh Media Pembelajaran Berbasis Youtube terhadap Hasil Belajar IPA Siswa di Sekolah DasarAmalia Rizki Wulandari, Masturi , Fina Fakhriyah

DOI: https://doi.org/10.31004/edukatif.v3i6.1251

menyajikan konten materi yang terdiri dari audio visual. Sehingga mampu menarik minat siswa untuk menyimak kegiatan pembelajaran. Dalam sistem pembelajaran daring saat ini, media berbasis youtube yang berbentuk video pembelajaran sangat membantu proses pembelajaran karena tidak mengharuskan bertatapmuka dalam pemberian materi kepada siswa. Cara agar video pembelajaran sampai kepada siswa guru hanya membagikan link youtube untuk dibuka sehingga siswa dengan mudah mengaksesnya.

Hal ini sejalan dengan media kartu bergambar dalam pembelajaran IPA kompetensi daur hidup organisme dalam proses belajar mengajar dapat menarik perhatian dan minat siswa. Pembelajaran seperti ini diharapkan dapat menjadi wahana bagi siswa untuk mempelajari diri sendiri dan lingkungannya, serta penerapan lebih lanjut dalam kehidupan sehari-hari (Masturi, Fina Fakhriyah, Mila Roysa, 2014). Hal ini relevan terhadap penelitian yang telah dilaksanakan bahwa media pembelajaran memiliki tujuan yang yang sama yaitu kemampuan siswa yang lebih baik.

Penelitian ini memiliki kelebihan karena menggunakan media pembelajaran berbasis youtube yang terdapat video pembelajaran yang dibuat oleh peneliti. Bersisi materi pembelajaran IPA yang belum dilakukan guru pada proses pembelajaran. Sehingga media pembelajaran berbasis youtube ini dapat mempengaruhi hasil belajar IPA siswa sekolah dasar. Tujuan penelitian ini yaitu untuk mengetahui pengaruh media pembelajaran berbasis youtube terhadap hasil belajar IPA siswa sekolah dasar.

\section{METODE PENELITIAN}

Penelitian ini dilakukan di SDN Karangsari 01 dan SDN Karangsari 03, Kecamatan Cluwak, Pati. Dalam penelitian ini menggunakan metode Quasi Eksperimental Design. Dengan desain The Nonequivalent pretest-posttest control-group. Desain penelitian ini terdapat dua kelompok, yaitu kelompok eksperimen dan kelompok kontrol. Populasi dalam penelitian ini yaitu siswa kelas 5 SD N Karangsari 01 dan SD Karangsari 03 yang berjumlah 26 siswa. Teknik pengambilan sampel menggunakan Teknik sampling jenuh karena jumlah populasi relatif kecil. Menurut (Sugiyono, 2014) Teknik sampling jenuh adalah teknik penentuan sampel bila semua anggota populasi digunakan sebagai sampel. Dalam penelitian ini menggunakan teknik sampling jenuh karena jumlah populasi relatif kecil sehingga jumlah populasi digunakan sebagai sampel yang berjumlah 26 siswa.

Teknik pengumpulan data menggunakan teknik wawancaara dan tes. Pengumpulan data melalui wawancara dilakukan dengan memberikan serangkaian pertanyaan yang diajukan secara langsung oleh peneliti kepada responden (Lestari \& Yudhanegara, 2015). Pengumpulan data melalui teknik tes dilakukan dengan memberikan instrument tes yang terdiri dari seperangkat pertanyaan atau soal untuk memperoleh data mengenai kemampuan siswa terutama pada aspek kognitif (Lestari \& Yudhanegara, 2015). Dalam penelitian ini teknik pengumpulan data yang digunakan yaitu tipe tes uraian berjumlah 12 soal. Soal tes diberikan 2 kali, yaitu pada pre-test untuk mengukur kemampuan awal siswa sebelum diberi perlakuan menggunakan media pembelajaran berbasis youtube dan post-test yang diberikan setelah diberi perlakuan untuk mengetahui ada tidaknya pengaruh media pembelajaran berbasis youtube terhadap hasil belajar siswa. Sebelum digunakan, tes dianalisis validitas dan reliabilitas butir soal terlebih dahulu. Dalam penelitian ini menggunakan uji hipotesis dengan uji-t dua sampel independen. Sebelum dilakukan uji hipotesis data yang dihasilkan harus diuji prasyarat yaitu uji normalitas dan uji homogenitas. Dalam menganalisis data penelitian ini menggunakan program SPSS 17 dengan taraf signifikan $\alpha=0,05$.

\section{HASIL DAN PEMBAHASAN PENELITIAN}

Berdasarkan penelitian yang dilakukan di SDN Karangsari 01 dan SDN Karangsari 03 dapat diketahui bahwa hasil data kedua kelas sampel berasal dari keadaan yang sama. Kemudian kedua sampel diberikan 
3782 Pengaruh Media Pembelajaran Berbasis Youtube terhadap Hasil Belajar IPA Siswa di Sekolah DasarAmalia Rizki Wulandari, Masturi , Fina Fakhriyah

DOI: https://doi.org/10.31004/edukatif.v3i6.1251

perlakuan berbeda, untuk kelas eksperimen yaitu SDN Karangsari 01 diterapkan media pembelajaran berbasis youtube dan kelas control yaitu SDN Karangsari 03 diterapkan media pembelajaran dengan modul. Data analisis nilai post-test hasil belajar siswa dideskripsi sebagai berikut:

Tabel 1. Hasil Analisis Nilai Post-test Hasil Belajar

\begin{tabular}{ccc}
\hline Statistik & Kelas Eksperimen & Kelas Kontrol \\
\hline $\mathbf{N}$ & 13 & 13 \\
\hline Mean & $\mathbf{8 4 , 2 3}$ & $\mathbf{7 9 , 9 2}$ \\
\hline
\end{tabular}

Berdasarkan tabel 1 diatas bahwa nilai rata-rata kelas eksperimen lebih besar dari pada rata-rata kelas kontrol. Rata-rata hasil belajar siswa dengan menggunakan media pembelajaran berbasis youtube lebih tinggi dibandingkan rata rata hasil belajar siswa dengan tanpa menggunakan media pembelajaran berbasis youtube. Rata-rata hasil belajar kelompok siswa kelas eksperimen yang mengikuti pembelajaran IPA materi kalor dengan media berbasis youtube adalah 84,23, sedangkan rata-rata hasil belajar kelompok siswa kelas kontrol yang mengikuti pembelajaran IPA materi kalor tanpa menggunakan media pembelajaran berbasis youtube adalah 79,92. Dilihat dari rata-rata hasil belajar kelompok siswa kelas eksperimen yang mengikuti pembelajaran IPA materi kalor dengan media berbasis youtube lebih tinggi dibandingkan rata-rata hasil belajar kelompok siswa kelas kontrol yang mengikuti pembelajaran IPA materi kalor tanpa menggunakan media pembelajaran berbasis youtube.

Manfaat media video yaitu dapat menjadikan konten materi yang ada didalamya menjadi menarik dan dapat menarik minat siswa untuk menyimak materi yang disampaikan. Keadaan inilah yang menstimulus ingatan siswa lebih baik sehingga pada saat proses merangkum siswa berkonsentrasi penuh terhadap apa yang dipelajarinya. Hal tersebut sejalan dengan penelitian (Chrismawati Mirna, Ika Septiana, 2021) yang menyatakan bahwa proses pembelajaran berbantuan dengan media audio visual mengalami peningkatan.

Setelah dilakukan analisis diatas kemudian dilakukan uji normalitas dan homogenitas data sebagai berikut.

Tabel 2. Data Hasil Uji Normalitas Data Akhir Hasil Belajar

\begin{tabular}{ccccc}
\hline \multicolumn{2}{c}{ Data } & $\begin{array}{c}\text { Kolmogorov- } \\
\text { Smirnov }\end{array}$ & $\begin{array}{c}\text { Asymp Sig } \\
(\text { 2-tailed })\end{array}$ & $\begin{array}{c}\text { Hasil } \\
\text { Kesimpulan }\end{array}$ \\
\hline \multirow{2}{*}{ Eksperimen } & $\begin{array}{c}\text { Post-test } \\
\text { Hasil Belajar } \\
\text { IPA }\end{array}$ & 0,923 & 0,361 & $\begin{array}{c}\text { Berdistribusi } \\
\text { Normal }\end{array}$ \\
& $\begin{array}{c}\text { Post-test } \\
\text { Hasil Belajar } \\
\text { IPA }\end{array}$ & 1,079 & 0,194 & $\begin{array}{c}\text { Berdistribusi } \\
\text { Normal }\end{array}$ \\
& & & & \\
\hline
\end{tabular}

Berdasarkan pada tabel 2 di atas, dilakukan uji normalitas data menggunakan Kolmogorov-Smirnov. Dalam kelas eksperimen diperoleh nilai Asymp Sig Kolmogorov-Smirnov hasil post-test belajar IPA sebesar 0,361 > 0,05. Dalam kelas kontrol diperoleh nilai Asymp Sig Kolmogorov-Smirnov hasil post-test belajar IPA sebesar 0,194 > 0,05. Hasil ini menunjukkan bahwa data pre-test dan post-test kelas eksperimen dan kelas kontrol berdistribusi normal. 
3783 Pengaruh Media Pembelajaran Berbasis Youtube terhadap Hasil Belajar IPA Siswa di Sekolah DasarAmalia Rizki Wulandari, Masturi, Fina Fakhriyah

DOI: https://doi.org/10.31004/edukatif.v3i6.1251

Tabel 3. Data Hasil Uji Homogenitas Data Akhir Hasil Belajar

\begin{tabular}{cccc}
\hline $\begin{array}{c}\text { Data Kelas } \\
\text { Eksperimen\&Kontrol }\end{array}$ & $\begin{array}{c}\text { Levene } \\
\text { Statistic }\end{array}$ & Sig & Kesimpulan \\
\hline $\begin{array}{c}\text { Post-test Hasil Belajar } \\
\text { IPA }\end{array}$ & 0,118 & 0,734 & Homogen \\
\hline
\end{tabular}

Berdasarkan tabel 3 diatas, dilakukan uji homogenitas menggunakan uji Levene Statistic diperoleh nilai Sig. pada Levene Statistic hasil post-test belajar IPA kelas eksperimen-kontrol 0,734>0,05. Dari hasil tersebut menunjukkan bahwa data bersifat homogen.

Tabel4. Hasil Uji-t Post-test Hasil Belajar IPA Kelas Eksperimen dan Kelas Kontrol

\begin{tabular}{ccccc}
\hline Data & T & df & Sig.(2-tailed) & Kesimpulan \\
\hline $\begin{array}{c}\text { Post-test } \\
\text { Eksperimen- } \\
\text { Kontrol }\end{array}$ & 3.891 & 24 & 0,001 & $\begin{array}{c}\text { Ada pengaruh } \\
\text { yang signifikan }\end{array}$ \\
\hline
\end{tabular}

Berdasarkan tabel 4 diatas, diperoleh data uji-t post-test hasil belajar IPA kelas eksperimen dan kelas kontrol berbantuan SPSS 17 dengan nilai sig. (2-tailed) 0,001<0,05. Maka dapat disimpulkan bahwa Ho ditolak dan Ha diterima sehingga terdapat perbedaan yang signifikan antara post-test hasil belajar IPA kelas eksperimen dan kelas kontrol. Perbedaan ini juga terdapat dalam nilai rata-rata post-test hasil, belajar IPA kelas eksperimen sebesar 84,23 dan nilai rata-rata post-test kelas kontrol sebesar 79,92. Maka berdasarkan hasil data tersebut kelas eksperimen memiliki rata-rata nilai hasil belajar IPA lebih tinggi dibandingkan kelas kontrol. Kemudian data tersebut dilakukan uji normalitas, homogenitas data dan uji hipotesis. Hasil uji hipotesis menunjukkan bahwa dengan nilai sig. (2-tailed) 0,001 < 0,05. Maka dapat disimpulkan bahwa Ho ditolak dan Ha diterima maka terdapat pengaruh penggunaan media pembelajaran berbasis youtube terhadap hasil belajar IPA siswa sekolah dasar.

Berdasarkan penelitian di atas, dapat diketahui bahwa media pembelajaran berbasis youtube dapat dijadikan pilihan yang tepat sebagai media pembelajaran saat kondisi pembelajaran daring. Menurunya hasil belajar siswa dikarenakan kurangnya siswa dalam memahami materi yang di sampaikan oleh guru saat proses pembelajaran. Hasil Belajar Ipa Siswa Kelas V Sekolah Dasar Tema 7 Materi Kalor dengan media pembelajaran berbasis youtube menunjukkan hasil lebih baik dari pada siswa yang tidak menggunakan media pembelajaran berbasis youtube, disebabkan karena pengaruh media pembelajaran sehingga siswa tertarik untuk mengikuti proses pembelajaran dan mendapatkan hasil belajar yang lebih baik. Dilihat dari manfaatnya kelebihan youtube sebagai media pembelajaran. Hasil belajar IPA siswaV sekolah dasar tema 7 materi kalor dengan menggunakan media berbasis youtube lebih baik dari pada siswa yang menggunaka media pembelajaran seperti biasa. Hasil penelitian ini sejalan dengan penelitian yang dilakukan sebelumnya oleh (Febriani et al., 2017) yang menyatakan bahwa terdapat pengaruh positif pada pembelajaran IPA yang menggunakan media video dibandingkan dengan pembelajaran IPA yang tidakmenggunakan media video.

Proses pembelajaran yang aktif dan efektif perlu menggunakan media pembelajaran dan sumber belajar yang dapat mendukung proses pembelajaran. Agar materi dalam proses pembelajaran dapat tersampaikan dengan baik kepada siswa dan relevan dengan penelitian oleh (Viviantini, Amram Rede, 2015) bahwa pembelajaran mengunakan media video pembelajaran berpengaruh signifikan terhadap hasil belajar Ipa siswa kelas VI SDN 6 Kayumalue Ngapa. Sehingga penelitian oleh (Maheswari \& Pramudiani, 2021) menyatakan bahwa media audio visual animaker memberikan pengaruh yang signifikan terhadap motivasi belajar IPA di kelas IV SDN Pekayon 12. Hal ini sejalan dengan hasil dalam penelitian oleh (Pambudi et al., 2018) menunjukkan bahwa pengaruh media video youtube dapat mempengaruhi prestasi belajar matematika pada siswa. Hasil penelitian (Yuliana \& Aminullah, 2020) yang menunjukkan bahwa pengaruh media video 
youtube dapat meningkatkan motivasi dan hasil belajar siswa. Penelitian oleh (Astriyani \& Fajriani, 2020) menunjukkan bahwa adanya pengaruh media audio visual youtube materi phythagoras terhadap keaktifan belajar matematika siswa dan relevan dengan penelitian oleh (Putri, 2021) membuktikan bahwa media pembelajaran power point memberikan pengaruh terhadap hasil belajar IPS siswa. Hal ini sejalan dengan (Fatmawati et al., 2018) yang menyatakan bahwa terdapat perbedaan hasil belajar siswa dalam pembelajaran biologi dengan menggunakan media youtube. Sehingga hasil dalam penelitian diatas sesuai dengan penelitian ini bahwa media pembelajaran berbasis youtube dapat mempengaruhi hasil belajar IPA siswa.

Keterbatasan dalam melaksanakan penelitian ini yaitu proses penelitian dilaksanakan secara virtual. Dalam penelitian, peneliti memiliki keterbatasan jaringan dan kuota internet yang dialami oleh peneliti dan siswa. Sehingga dalam proses pembelajaran mengguankan media berbasis youtube ini penayangan video yang ada dalam youtube menjadikurang maksimal. Dengan keterbatasan yang ada proses penelitian ini melakukan sesuai dengan prosedur yang telah dirancang dengan baik sesuai dengan rencana proses pemebelajaran.

\section{KESIMPULAN}

Berdasarkan hasil pembahasan penelitian ini, maka dapat disimpulkan bahwa kelas yang melaksanakan proses pembelajaran menggunakan media berbasis youtube memiliki hasil belajar IPA yang lebih baik dibandingkan kelas yang tidak menggunakan media pembelajaran berbasis youtube pada siswa kelas V SDN Karangsari 01 dan SDN Karangsari 03. Siswa terlihat lebih bersemangat dan lebih aktif dalam mengikuti proses pembelajaran secara daring. Hal ini terlihat dari data hasil uji- $t$ post-test hasil belajar IPA kelas eksperimen dan kelas kontrol dengan nilai sig. (2-tailed) 0,001<0,05. Maka dapat disimpulkan bahwa Ho ditolak dan Ha diterima yang artinya ada perbedaan yang signifikan antara post-test hasil belajar IPA kelas eksperimen dan kelas kontrol. Sehingga terdapat pengaruh penggunaan media pembelajaran berbasis youtube terhadap hasil belajar IPA siswa sekolah dasar.

\section{UCAPAN TERIMA KASIH}

Dengan ini penulis mengucapkan terimakasih kepada SDN Karangsari 01 dan SDN Karangsari 03 Kecamatan Cluwak Kabupaten Pati yang telah memberikan ijin pelaksanaan penelitian di kelas 5 . Selanjutnya, terimakasih kepada Ibu Sunarti S.Pd selaku guru kelas 5 SDN Karangsari 01 dan Ibu Roikhatul Mufidah S.Pd.,M.Pd selaku guru kelas 5 SDN Karangsari 03 yang telah membantu dalam proses pelaksanaan penelitian secara daring ini.

\section{DAFTAR PUSTAKA}

Arfani, L. (2018). Mengurai Hakikat Pendidikan, Belajar Dan Pembelajaran. Pelita Bangsa Pelestari Pancasila, 11(2).

Astriyani, A., \& Fajriani, F. (2020). Pengaruh Penggunaan Media Audio Visual Youtube Materi Pythagoras Terhadap Keaktifan Belajar Matematika Siswa. FIBONACCI: Jurnal Pendidikan Matematika Dan Matematika, 6(1), 87-90. Https://Dx.Doi.Org/10.24853/Fbc.6.1.87-90.

Bugiardo, D. (2015). Berkomunikasi Ala Net-Generation. Elex Media Komputindo.

Cahyani, A., Listiana, I. D., \& Larasati, S. P. D. (2020). Motivasi Belajar Siswa SMA Pada Pembelajaran Daring Di Masa Pandemi Covid-19. IQ (Ilmu Al-Qur'an): Jurnal Pendidikan Islam, 3(01), 123-140. Https://Doi.Org/10.37542/Iq.V3i01.57

Chrismawati Mirna , Ika Septiana, E. D. P. (2021). Edukatif : Jurnal Ilmu Pendidikan Peningkatan Hasil Belajar IPA Dengan Discovery Learning Berbantuan Media Audio Visual Di Sekolah Dasar. Ilmu 
3785 Pengaruh Media Pembelajaran Berbasis Youtube terhadap Hasil Belajar IPA Siswa di Sekolah DasarAmalia Rizki Wulandari, Masturi , Fina Fakhriyah

DOI: https://doi.org/10.31004/edukatif.v3i6.1251

Pendidikan, 3(3), 698-704.

Fatmawati, A., Nofisulastri, N., Adawiyah, S. R., \& Devi, N. S. (2018). Perbedaan Hasil Belajar Siswa Dalam Pembelajaran Biologi Dengan Menggunakan Media Youtube Di Ma Annajah Ponpes Al Halimy Sesela. Bioscientist : Jurnal Ilmiah Biologi, 6(1), 58. Https://Doi.Org/10.33394/Bjib.V6i1.2366

Febriani, C., Palangka, U., Jalan, R., Sudarso, Y., Raya, J., \& Raya, K. P. (2017). Jurnal Prima Edukasia , 5 ( 1 ), 2017 , 11-21 Pengaruh Media Video Terhadap Motivasi Belajar Dan Hasil Belajar Kognitif Pembelajaran IPA Kelas V Sekolah Dasar The Effect Of Video Media On Learning Motivation And Cognitif Learning Outcomes In Natural Scien. 5(1), 11-21.

Jannah, M., \& Nurdiyanti. (2021). Pengaruh Pembelajaran Online Berbantuan Google Classroom Terhadap Hasil Belajar Siswa. Jurnal Riset Dan Inovasi Pembelajaran, 1(1), 75-84.

Lestari, K. E., \& Yudhanegara, M. R. (2015). Penelitian Pendidikan Matematika. Bandung: PT Refika Aditama, 2(3).

Maheswari, G., \& Pramudiani, P. (2021). Edukatif: Jurnal Ilmu Pendidikan Pengaruh Penggunaan Media Audio Visual Animaker Terhadap Motivasi Belajar IPA Siswa Sekolah Dasar. 3(5), 2531-2538.

Masturi, Fina Fakhriyah, Mila Roysa, I. F. (2014). Pengaruh Penggunaan Media Kartu Bergambar Terhadap Kemampuan Mendeskripsikan Daur Hidup Organisme Dilihat Dari Tingkat Kemandirian Belajar Siswa Di SD 5 Dersalam Kudus. Jurnal Sosial Dan Budaya, 7(Vol 7, No 1 (2014)), 39-44. Https://Jurnal.Umk.Ac.Id/Index.Php/Sosbud/Article/View/542

Pambudi, R., Afghohani, A., \& Farahsanti, I. (2018). Pengaruh Media Video Youtube Terhadap Prestasi Belajar Matematika Pada Siswa Kelas X SMK Negeri 2 Sukoharjo Tahun Ajaran 2017 / 2018. Jurnal Pendidikan, 28(2), 175-182.

Putri, H. P. (2021). Edukatif: Jurnal Ilmu Pendidikan Pengaruh Media Pembelajaran Power Point Interaktif Terhadap Hasil Belajar IPS Siswa Sekolah Dasar. 3(6), 3538-3543.

Rusman. (2013). Model-Model Pembelajaran "Mengembangkan Profrsi Guru. Rajawali Pers.

Salam, R. (2017). Model Pembelajaran Inkuiri Sosial Dalam Pembelajaran IPS. Harmony: Jurnal Pembelajaran IPS Dan PKN, 2(1), 7-12.

Sudjana, N. (2011). Penilaian Hasil Proses Belajar Mengajar. PT Remaja Rosdakarya.

Sugiyono. (2014). Metode Penelitian Kuantitatif Kualitatif Dan R\&D. Alfabeta.

Viviantini, Amram Rede, S. S. (2015). Pengaruh Media Video Pembelajaran Terhadap Minat Dan Hasil Belajar IPA Siswa Kelas Vi SDN 6 Kayumalue Ngapa. Jurnal Sains Dan Teknologi Tadulako, 4(1), 6671. Http://Jurnal.Untad.Ac.Id/Jurnal/Index.Php/JSTT/Article/Download/6930/5569

Yuliana, D., \& Aminullah, N. F. (2020). Pengaruh Media Video Youtube Terhadap Motivasi Dan Hasil Belajar Siswa Kelas Xi Simulasi Digital Di Smk Negeri 1 Suboh. Jurnal Pendidikan Dan Kewirausahaan, 8(1), 37-53. Https://Doi.Org/10.47668/Pkwu.V8i1.61

Zayyadi, M., Supardi, L., \& Misriyana, S. (2017). Pemanfaatan Teknologi Komputer Sebagai Media Pembelajaran Pada Guru Matematika. Jurnal Pengabdian Masyarakat Borneo, 1(2), 25. Https://Doi.Org/10.35334/Jpmb.V1i2.298 